\title{
Discrimination training in infant, preweanling, and weanling rats: Effects of prior learning experiences with the discriminanda
}

\author{
STEPHEN C. BRAKE \\ The University of Texas, Austin, Texas 78712
}

\begin{abstract}
Rats were given continuous reinforcement (CRF), partial reinforcement (PRF), or successive discrimination (D) training in an alley from 11-14 (Age 1) or 15-18 (Age 2) days of age. Reinforcement was the opportunity to suckle the dry nipples of an anesthetized dam. Following a 10-day interval, all animals were given 4 successive days of discrimination training with food pellets as reinforcement. Control groups were given only the second phase of training. In the first phase, D subjects of both ages responded appropriately to the discriminative stimuli, and the PRF subjects of both ages ran significantly slower than CRF subjects. In the second phase, only the CRF subjects of Age 1 showed behavioral discrimination. All three Age 2 groups discriminated, but the discrimination developed earliest after Phase I CRF and latest after Phase I PRF. Both Age 1 control groups showed a latedeveloping discrimination, but neither Age 2 control group discriminated. The results suggest that infant and preweanling rats can learn both positive and negative expectancies of appetitive events, respond appropriately, and retain and transfer these expectancies to new learning. The reinforcement value of dry suckling and the effects of stimulus preexposure in infant rats are also discussed.
\end{abstract}

Two hypotheses concerning learning and memory processes in preweanling rats have received renewed attention within recent years. The first of these states that learned associations are poorly retained in young animals. A number of experiments support this this hypothesis. Weanlings between 20 and 25 days of age receiving active avoidance training (Campbell \& Campbell, 1962; Campbell, Misanin, White, \& Lytle, 1974; Egger \& Livesey, 1972; Kirby, 1963), escape training (Smith, 1968), or appetitive discrimination training (Campbell, Jaynes, \& Misanin, 1968) show limited retention of these tasks following intervals of from 1 to 9 weeks. Coulter, Collier, and Campbell (1976), however, suggested that changing perception of apparatus cues might be in part responsible for the poor performance of animals trained as weanlings and tested later, and that the conditioned responses themselves might be well retained. They demonstrated this to be true for animals as young as 16 days of age, but not 11 days of age, through the use of a CER paradigm.

Supported by Grant BMS 74-19696 from the National Science Foundation to Dr. Abram Amsel. This research is taken from a larger report submitted to the Graduate School of the University of Texas at Austin in partial fulfillment of the requirements for the PhD degree. The author gratefully acknowledges the guidance and encouragement offered by Dr. Abram Amsel throughout every phase of this project. Requests for reprints should be sent to Stephen C. Brake, who is now with the Department of Psychiatry, Montefiore Hospital and Medical Center, 111 East 210th Street, Bronx, New York 10467.
The second hypothesis is that young rats have difficulty performing responses that involve the inhibition of ongoing behavior. Animals younger than about 25 days of age are apparently limited in their ability to learn passive avoidance responses of various kinds (Brunner, 1969; Campbell et al., 1974; Egger \& Livesey, 1972; Feigley \& Spear, 1970; Riccio, Rohrbaugh, \& Hodges, 1968), do not show spontaneous alteration as reliably as adult rats do (Douglas, 1975), and are slow to habituate compared to adults (Bronstein, Neiman, Wolkoff, \& Levine, 1974; Campbell \& Mabry, 1972; Feigley, Parsons, Hamilton, \& Spear, 1972). In addition, observations of a more naturalistic sort suggest a lack of behavioral inhibition in nursing rats. Pups suckling a lactating dam obtain a brief burst of milk only about once every 10-15 min (Lincoln, Hill, \& Wakerley, 1973; Wakerley \& Drewett, 1975). Nevertheless, bursts of suckling occur much more frequently (Drewett, Statham \& Wakerley, 1974; Brake, Wolfson, \& Hofer, Note 1), and pups younger than about 15 days of age will remain on the dry nipples of an anesthetized dam for up to $3 \mathrm{~h}$ without interruption (Hall, Cramer, \& Blass, 1975; Brake et al., Note 1). This relative inability to "inhibit" responses seems to be negatively correlated with the maturation of rostral, cholinergic CNS structures, notably the hippocampus (Campbell, Lytle, \& Fibiger, 1969; Douglas, Peterson, \& Douglas, 1973; Egger, Livesey, \& Dawson, 1973; Moorcroft, 1971), and several investigators have suggested that in- 
hibition depends largely on the functional maturity of these systems and structures (Altman, Brunner, \& Bayer, 1973; Douglas, 1975).

A series of recent studies (Amsel \& Chen, 1976; Burdette, Brake, Chen, \& Amsel, 1976; Chen \& Amsel, 1975; Brake, Burdette, Chen, \& Amsel, Note 2) suggest that infant and preweanling rats are able to retain early-learned appetitive behaviors and inhibit learned approach responses quite well. Specifically, the experiments demonstrate that weanling-aged animals retain persistence learned during partial reinforcement (PRF) runway training after intervals of 10-45 days. Further, the rate of extinction for weanling-aged animals trained under CRF conditions was similar to that of adults. Even more recent data (Amsel, Burdette, \& Letz, 1976; Amsel, Letz, \& Burdette, 1977) indicate that subjects as young as 11 days of age are able to learn and extinguish an approach response when reinforcement is the opportunity to suckle the "dry" nipple of an anesthetized dam. Still, simple response extinction does not provide a very informative demonstration of response inhibition as various motivational hypotheses may be employed to explain diminished instrumental performance. And these experiments offer no demonstration of long-term retention of the learned responses.

The infant rats' ability to retain conditioned instrumental responses and respond appropriately to aversive stimuli can be convincingly demonstrated through successive (go, no-go) discrimination training in the straight alley. During the early stages of this procedure, the animal is on an effective PRF schedule (Amsel, 1962; Amsel \& Ward, 1965). As training procedes, the animal should continue to run quickly from the neutral startbox, but slow or stop in the presence of $\mathrm{S}-$. This provides a rather dramatic demonstration of response "inhibition." An even more sophisticated procedure is to study the acquisition of the discrimination following a number of prior learning experiences with the discriminanda ("prediscrimination" treatment). A retention interval may be interpolatd between prediscrimination treatment and subsequent discrimination training, allowing us to measure retention of more than one conditioned "expectancy"' by observing how subsequent discrimination learning is effected by the earlier learning.

Three prediscrimination treatments, CRF, PRF, and "reversed" successive discrimination, will provide particularly useful information. Adult rats given equal preexposure to two different stimuli during CRF training $\left(S_{1}+S_{2}+\right)$ subsequently show marked facilitation of behavioral discrimination with the two preexposed stimuli as discriminanda $\left(S_{1}+S_{2}-\right)$, relative to animals given no preexposure prior to discrimination training. Preexposure during PRF training $\left(S_{1} \pm S_{2} \pm\right)$, in which neither stimulus differentially predicts presence or absence of reinforcement, retards subsequent dis- crimination performance. Finally, prior discrimination training with the discriminanda values reversed from what they are in the subsequent test $\left(S_{1}-\right.$ later becoming $S_{1}+, S_{2}+$ becoming $S_{2}-$ ) results in initially retarded performance to the new $\mathrm{S}+($ old $\mathrm{S}-$ ) and initially facilitated performance to the new $\mathrm{S}-$ (old $\mathrm{S}+$ ), providing a conclusive measure of response inhibition. These effects can be ascribed to the relative strength of conditioned approach and avoidance tendencies acquired during the prediscrimination treatment (Amsel, 1962; Amsel $\&$ Ward, 1965). Thus we have sophisticated measures of both response inhibition and retention of original learning.

There have been few appetitive discrimination studies employing rats younger than 25 days of age as subjects, and none employing a prediscrimination treatment. Campbell and his associates (Campbell, 1967; Campbell et al., 1968; Campbell \& Randall, 1976) and Roberts (1966) found that 20- to 25-day-old rats have little trouble learning simultaneous or successive discriminations. Of course, animals of this age are able to perform most "inhibitory" tasks well so that differential performance to $\mathrm{S}+$ and $\mathrm{S}-$ should not, perhaps, be unexpected. Retention of discrimination training was found to be poor (Campbell et al., 1968) unless periodic reexposures to the stimuli were given (Campbell \& Randall, 1976). With respect to infants, Bulut and Altman (1974) reported that 6-, 10-, and 15-day-old animals were able to learn both spatial and tactile discriminations in a choice apparatus when the reinforcing agent was access to the home-cage nest environment. Each of the three age groups learned by Day 20 when behavioral discrimination might be expected on the basis of the other data, but none before Day 18 . No retention data were reported. The most convincing demonstration of response inhibition and retention to date is reported by Kenny and Blass (1977). In an experiment similar in some ways to the present study, they showed that infants as young as 7 days are able to learn and reverse simple spatial discriminations as well as retain original learning for 2 days.

In the present study, infant rats were preexposed to two discrete stimuli during three different reinforcement schedules, CRF, PRF, and D (successive discrimination), with dry suckling as reinforcement. Successive discrete stimulus presentations were employed in the discrimination task in order to measure the degree of behavioral control accruing to the discriminanda during the course of training. Ten days after initial learning, all animals were trained on a second successive discrimination (with food reinforcement) using the preexposed stimuli as discriminanda. The entire treatment was designed to aid in understanding exactly which conditioned tendencies were learned and retained. Animals which had not received preexposure to the discriminanda were run in the latter phase as control groups. 


\section{METHOD}

\section{Subjects}

The experimental subjects were pups drawn from the litters of Holtzman albino dams bred in our laboratory. Each litter was culled to nine pups 2 days after birth. One day prior to the beginning of Phase I runway training (or treatment for controls), 30 subjects were drawn from a pool of approximately 80 pups. These pups were assigned to two age groups and were placed in litters of six with five different foster mothers. These 30 constituted three experimental and two control groups at each age. This entire procedure was followed for each of two replications.

\section{Apparatus}

Two separate runways, a small-alley runway and a large-alley runway were used. The small-alley runway consisted of a $12.0 \times$ $5.8 \times 5.1 \mathrm{~cm}$ startbox and a $53.0 \times 5.8 \times 5.1 \mathrm{~cm}$ run alley. The large-alley runway consisted of a $27 \times 7.6 \mathrm{~cm}$ startbox and a $103 \times 7.6 \times 7.6 \mathrm{~cm}$ run alley. Each runway could be aligned with a $32.7 \times 27.5 \times 18.5 \mathrm{~cm}$ goalbox. The goalbox was divided into two compartments by a wiremesh screen. The front chamber, which measured $32.7 \times 14.0 \times 18.5 \mathrm{~cm}$, was where the reinforcing stimulus (anesthetized dam or food pellet) was placed on reinforced trials. The rear chamber, which measured $32.7 \times$ $13.5 \times 18.5 \mathrm{~cm}$, separated the front chamber from an exhaust fan located on the rear wall of the goalbox. This fan was designed to draw air from four holes in the floor to the rear of the goalbox. By inserting a U-shaped Plexiglas barrier, the front chamber could be restricted to $13.0 \times 14.0 \times 8.5 \mathrm{~cm}$. This was done when food was used as reinforcement. At the same time, a small, glass Petrie dish was placed along the back wall of the barrier and served as a goal cup. The run alleys of both runways were painted flat black. In both, two different floorboards, also painted flat black, could be inserted. One was wiremesh of $1.3 \times 1.3 \mathrm{~cm}$ hardware cloth, the other, smooth Plexiglas. The wooden startboxes and the goalbox were painted gray. Opaque guillotine doors separated the startboxes of each runway from their respective alleys. Both runways were covered with Plexiglas. Running speeds were recorded by photoelectric circuitry.

\section{Design and Procedure}

The experiment was run in two replications. In both, three groups at each of two ages received both Phase I and Phase II runway training and two groups received only differential handling treatment in Phase I before runway training in Phase II. The design is shown in Table 1.

Phase 1. Three groups of rat pups, six per group (three per replication) received prediscrimination training over 4 consecutive days at each of two ages, 11-14 days (Age 1) and 15-18 days (Age 2). One group of subjects received reward on every trial (CRF), while the other groups received reward on $50 \%$ of the trials in a quasi-random order (PRF and D). One session, consisting of 32 trials and lasting 5-6 h was run on each of 4 days at each age. Twelve to 14 hours prior to each session, the pups were placed together without the foster mother in a plastic "waiting cage," the floor of which was covered with clean sawdust shavings and maintained at a temperature of $36^{\circ}-38^{\circ} \mathrm{C}$. The first session was run in the small-alley apparatus to facilitate the initially poor performance of these very young animals. The next three sessions were run in the large-alley apparatus. At the conclusion of each session, the pups were returned to the foster mothers and remained with them for 6-8 $\mathrm{h}$. Pups were weighed each day before separation and after runway training. The deprivation procedure resulted in a mean net weight loss of $3.8 \mathrm{~g} /$ day for Age 1 animals and $5.8 \mathrm{~g} /$ day for Age 2 animals, maintaining them at approximately $86 \%$ and $83 \%$ body weight, respectively, compared to nondeprived weight controls.
Table 1

Design of Runway Training Contingencies

\begin{tabular}{|c|c|c|c|c|}
\hline & \multicolumn{4}{|c|}{ Ages 1 and 2} \\
\hline & \multicolumn{2}{|c|}{ Phase 1} & \multicolumn{2}{|c|}{ Phase 2} \\
\hline \multirow{2}{*}{$\mathrm{D}$} & $S_{1}+$ & $\mathrm{S}_{2}-$ & $\underline{S_{1}-}$ & $\mathrm{S}_{2}+$ \\
\hline & $S_{1}-$ & $\mathrm{S}_{2}+$ & $S_{1}+$ & $\mathrm{S}_{2}-$ \\
\hline \multirow{2}{*}{ PRF } & \multirow{2}{*}{$S_{1} \pm$} & \multirow{2}{*}{$S_{2} \pm$} & $\underline{S_{1}-}$ & $\mathrm{S}_{2}+$ \\
\hline & & & $S_{1}+$ & $\mathrm{S}_{2}-$ \\
\hline \multirow{2}{*}{ CRF } & \multirow{2}{*}{$S_{1}+$} & \multirow{2}{*}{$\mathrm{S}_{2}+$} & $S_{1}-$ & $\mathrm{S}_{2}+$ \\
\hline & & & $S_{1}+$ & $\mathrm{S}_{2}-$ \\
\hline \multirow{2}{*}{$\mathrm{T}$} & & & $S_{1}-$ & $\mathrm{S}_{2}+$ \\
\hline & & & $S_{1}+$ & $\mathrm{S}_{2}-$ \\
\hline \multirow{2}{*}{ UT } & & & $\underline{S_{1}-}$ & $\mathrm{S}_{2}+$ \\
\hline & & & $S_{1}+$ & $\mathrm{S}_{2}-$ \\
\hline
\end{tabular}

On each trial, for every subject, either the wire-mesh floorboard $\left(\mathrm{S}_{1}\right)$ or the Plexiglas floorboard $\left(\mathrm{S}_{2}\right)$ was inserted into the alley. $S_{1}$ and $S_{2}$ were presented to PRF subjects equally often in a quasi-random order such that neither stimulus was correlated with the presence or absence of reward; the probability of reward or nonreward on any given trial for PRF subjects was equal, 0.5 in both cases, regardless of which surface they had just crossed. For CRF pups, $S_{1}$ and $S_{2}$ were also presented équally often in a quasi-random order, but, of course, probability of reward on any given trial was 1.0. For one-half of the $D$ subjects, $S_{1}$ was perfectly correlated with reward $(S+)$ and $S_{2}$ was perfectly correlated with nonreward $(S-)$. For the remaining half of the subjects, $S_{2}$ served as $S+$ and $S_{1}$ as $S-$. Thus, the procedure followed for Group $D$ defines a $100 / 0$ successive discrimination.

Reward for all pups consisted of contact and suckling an anesthetized dam. Four to six dams were used for this purpose over the 4-day period, though only one was used at each age per session. The dams were from the remaining mothers from the original mother-pup subject pool, and were therefore on the same diet, and were nursing pups of the same age as the experimental subjects when not used in the training phase as reinforcing agents. One-half hour before runway training, the-dam received an IP injection of Equithesin, $0.2 \mathrm{cc} / 10 \mathrm{~g}$ body weight. This resulted in surgical-level anesthetization which lasted about $2 \mathrm{~h}$. A second injection, $.01 \mathrm{cc} / 10 \mathrm{~g}$ body weight, was then given to keep the dam under anesthesia until the session was completed. On two occasions, a dam died from an overdose and another was substituted. It is important to note that Equithesin in these dosages will prevent milk-ejection if only one pup is allowed to suckle at a time (Lincoln et al., 1973).

Prior to the first trial of the first session for both ages, all subjects were placed in the goalbox with the anesthetized dam for $5 \mathrm{~min}$. This was done in order to insure arousal of the pups and to elongate the nipples of the dam. A trial consisted of the following procedure: The anesthetized dam (if an $\mathrm{R}$ trial) was placed in the front chamber of the goalbox on her back, both rows of nipples exposed. The appropriate floorboard, $S_{1}$ or $S_{2}$, was inserted into the runway and the goalbox was lowered. The pup was then placed in the startbox and the startdoor was raised, beginning the trial. As the pup broke the last photobeam, located immediately in front of the goalbox, the goalbox door was raised revealing the goalbox. The pup was allowed to suckle for $15 \mathrm{sec}$ on an R trial or was confined to the goalbox for $15 \mathrm{sec}$ on an $\mathrm{N}$ trial, and was then returned to the "waiting cage." The intertrial interval was $10 \mathrm{~min}$. At the completion of Phase $\mathrm{I}$, on Day 14 or Day 18 , all subjects were returned to the foster mother 
and left undisturbed for 2 days. They were then weaned, housed individually, and fed Purina Rat Chow ad lib for 8 days.

Two groups of pups at both ages, treated $(T)$ and untreated (UT), received no runway training in Phase 1 . T subjects received deprivation identical to that of prediscrimination animals and were repeatedly handled for 5 min per day on each of the four Phase I training days. UT subjects were left undisturbed during this phase.

Phase II. Ten days after the completion of Phase I, all rats were food deprived for $24 \mathrm{~h}$. Beginning on Day 25 for Age 1 and on Day 29 for Age 2, four sessions of runway training were given at 32 trials per session, one session per day. The training was conducted entirely in the large-alley apparatus and with the goalbox dimensions restricted for food reinforcement. Reward consisted of one $97-\mathrm{mg}$ Noyes food pellet. Subjects in all five groups were run on a 100/0 successive discrimination. The discriminative stimuli, $S_{1}$ and $S_{2}$, were the same as those used in Phase I. For half the PRF, CRF, T, and UT subjects, $S_{1}$ served as $\mathrm{S}+$ and $\mathrm{S}_{2}$ as $\mathrm{S}-$, and for the remaining half, the reverse was the case. The stimuli that served as $\mathrm{S}+$ and $\mathrm{S}-$ for $\mathrm{D}$ subjects in Phase I became $S-$ and $S+$, respectively, that is, $D$ subjects were run on a discrimination in Phase II reverse from the discrimination they had run in Phase I. The intertrial interval was 10-15 min, and the $R$ and $N$ sequence was identical to that used in Phase I. Following each session, the subjects were fed $5 \mathrm{~g}$ (CRF) or $61 / 2 \mathrm{~g}$ (PRF and D). This deprivation schedule resulted in a maintainence of approximately $85 \%$ free-feeding body weight.

\section{RESULTS}

Running speed $(\mathrm{cm} / \mathrm{sec})$ was analyzed across four different measures: start, run, goal, and total. Analyses of variance were performed on four independent variables: age (two levels: Age 1 and Age 2), group (three levels: CRF, PRF, and D; or, in the case of the separately analyzed control animals, two levels: T and UT), blocks (eight levels: eight trials/block; two blocks constituted a session), and reinforcement. Reinforcement consisted of two levels, R-trial and $\mathrm{N}$-trial performance. Those CRF trials which occurred at the same time as $\mathrm{N}$ trials for PRF and D subjects were analyzed as " $N$ trials." (These corresponding $R$ trials occurred with the same stimulus presentation, $S_{1}$ or $S_{2}$, as did PRF $N$ trials). In Phase II, the two levels of the reinforcement variable were $\mathbf{R}$ trials and $\mathbf{N}$ trials for all subjects. Thus, each group is represented twice in each block, $8 \mathrm{R}$ trials and $8 \mathrm{~N}$ trials, giving a total of 16 trials per block, 32 trials per session. The two preliminary blocks of trials of Phase I were not included in the analysis of Phase I data because of the different nature of the training apparatus. For purposes of reporting statistical results, only the analyses performed on the total measure (start + run + goal $/ 3$ ) will be discussed; analyses on the other three measures were highly similar to the total analysis.

\section{Phase I}

Data for Age 1 and Age 2 are presented in Figures 1 and 2 , respectively. (Since analysis revealed no significant differences between $S_{1}$ and $S_{2}$ responding in CRF and PRF pups, or between R-trial and $\mathrm{N}$-trial responding in PRF pups, only one curve is

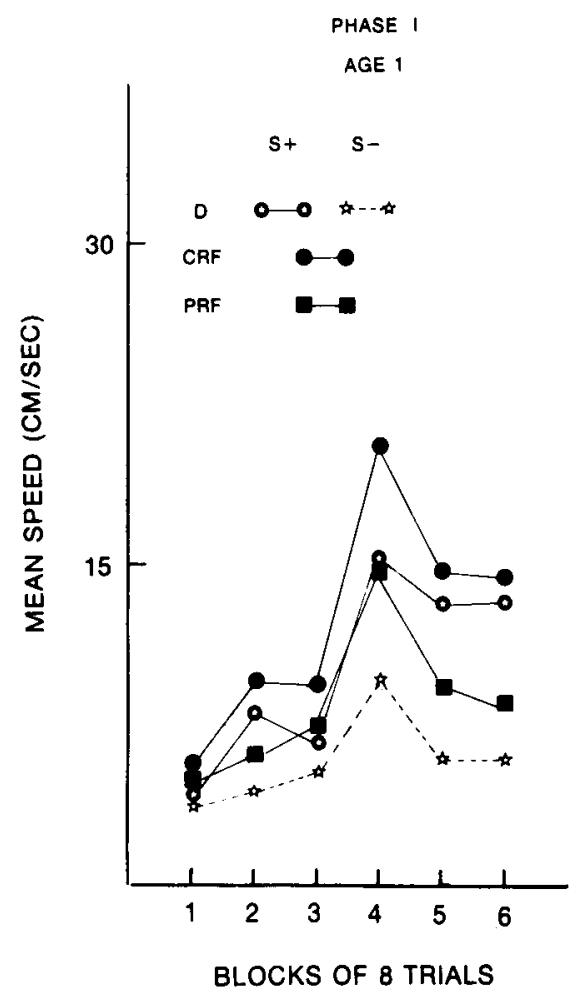

Figure 1. Mean speeds for Age 1 groups in Phase 1, excluding preliminary blocks (each CRF and PRF point represents responding to both $S_{1}$ and $S_{2}$ ).

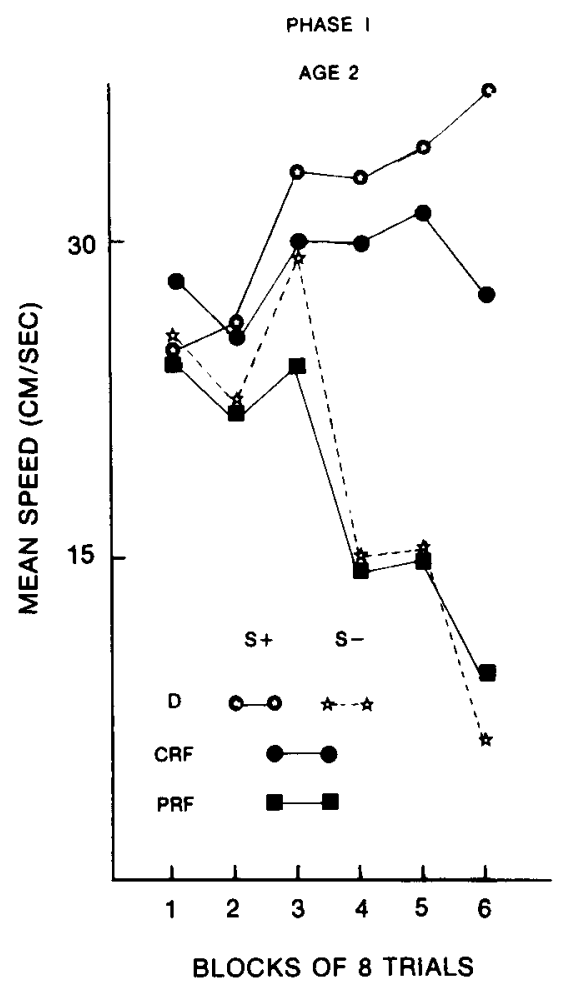

Figure 2. Mean speeds for Age 2 groups in Phase I, excluding preliminary blocks (each CRF and PRF point represents responding to both $S_{1}$ and $S_{2}$ ). 
shown for those groups in Figures 1 and 2.) All animals of both ages had already begun to acquire the approach response following the two preliminary blocks, and running speeds in Age 1 subjects continued to increase until Block 4, after which they declined somewhat. Running speeds for Age 2 subjects, however, were already close to asymptote by Block 1 and increased very little in any group thereafter. In short, the animals did learn to approach, with the younger animals taking longer and reaching lower absolute levels of speed. This is reflected statistically by significant Age $[F(1,48)=36.30, p<.001]$, Block $[\mathrm{F}(5,240)=15.39, \mathrm{p}<.001]$, and Age by Block $[F(5,240)=25.98, p<.001]$ effects. It is also clear that both CRF and PRF subjects at Age 1 show increasing speeds through Block 4, after which speeds decline. In Age 2, the CRF subjects maintain a high level of responding while performance in PRF subjects declines from Block 3 . This is confirmed by statistically significant Age by Group $[F(2,48)=$ 22.79, p <.001] and Age by Block by Group $[F(10,240)=3.74, p<.001]$ interaction effects. Finally, running speeds to $\mathrm{S}+$ and $\mathrm{S}-$ for $\mathrm{D}$ subjects of both ages clearly demonstrate behavioral discrimination, as shown by a significant Block by Group by Reinforcement interaction $[F(10,240)=$ $6.92, \mathrm{p}<.001]$, though the magnitude of the divergence is very different at the two ages, as demonstrated by a significant Age by Block by Group by Reinforcement interaction $[F(10,240)=4.07, p<$ .0011 .

Considering Age 1 separately, it is immediately obvious that CRF subjects as a whole ran faster throughout training than either PRF or D subjects, as confirmed by a significant Block by Group effect $[F(10,120)=3.61, p<.001]$ and by a significant orthogonal comparison between Group CRF and the combined Groups PRF and D, collapsed over Blocks [CRF vs. PRF $+\mathrm{D}, \mathrm{F}(1,24)=$ $7.93, \mathrm{p}<.01]$. This suggests that speed of acquisition was, at this age, a function of the number of rewarded trials. Notice that in later training, the speed of $D$ subjects on $R$ trials is faster than the speed of PRF subjects, while on $N$ trials, the speed of $D$ subjects is slower than that of PRF subjects $[P R F$ vs. $D$ by Reinforcement, $F(1,24)=9.06$, $\mathrm{p}<.01$ ]. Still, the orthogonal test PRF vs. D was significant,suggesting that PRF performance represents a reliable "averaging" of reward expectancies. The difference between groups is even more clear at Age 2. Again, CRF subjects ran faster throughout training than either PRF or D subjects, as confirmed by a significant Group by Block effect $[F(10,120)=$ $5.29, \mathrm{p}<.001]$. In fact, the PRF animals actually extinguished as training continued. Apparently, the incentive value of dry suckling is not enough to maintain responding at this age if reinforcements are interspersed with nonreinforcements, and when the subject cannot predict the occurrence or nonoccur- rence of reward on any trial. Interestingly, performance on $\mathrm{N}$ trials for the $\mathrm{D}$ subjects is almost identical to PRF performance and performance on $\mathrm{R}$ trials is identical to CRF performance. One might expect that the combined response tendencies (reward and nonreward) in the PRF subjects might result in performance somewhere between the two D curves. This was not the case, suggesting that nonreward does not merely decrease positive expectancy but is something more active. On the other hand, the fact that performance of PRF subjects at Age 1 was intermediate between $\mathrm{S}+$ and $\mathrm{S}$ - performance of $D$ animals suggests that the reinforcer was more effective at this age (compare Age 1 and Age 2 PRF performance), overcoming the avoidance tendency.

\section{Phase II}

The Phase II D, CRF, and PRF data at Age 1 and Age 2 are presented in Figures 3 and 4, respectively, and the T and UT control data in Figure 5. (Remember that subjects ran to food reinforcement in this phase.) As reflected in the high running speeds on the first two blocks of trials, animals of both ages reacquired the approach response very quickly and reached higher asymptotes than in Phase I. Their rates of acquisition were also much faster than the $T$ and UT control groups of both ages. Analysis of the first two blocks indicates that all groups run in Phase I were close to asymptote by the second of these two blocks; in Phase I, asymptote was approached much later. The controls reached asymptote by Block 6 . This result indicates some retention of positive reward expectancy over the 10-day interval. Even subjects trained under PRF in Phase $\mathbf{I}$, whose performance was poor at both

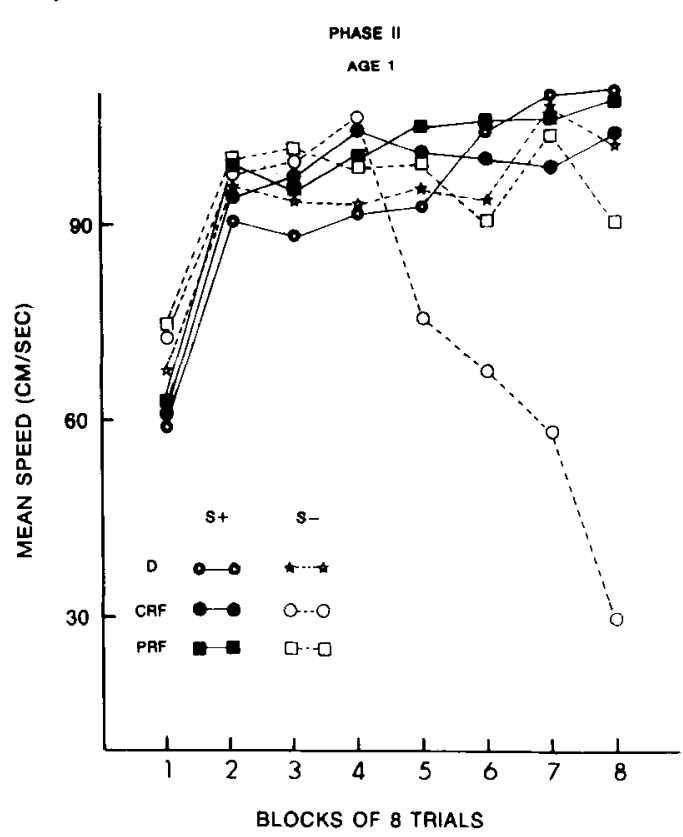

Figure 3. Mean speeds for Age 1 groups in Phase II. 


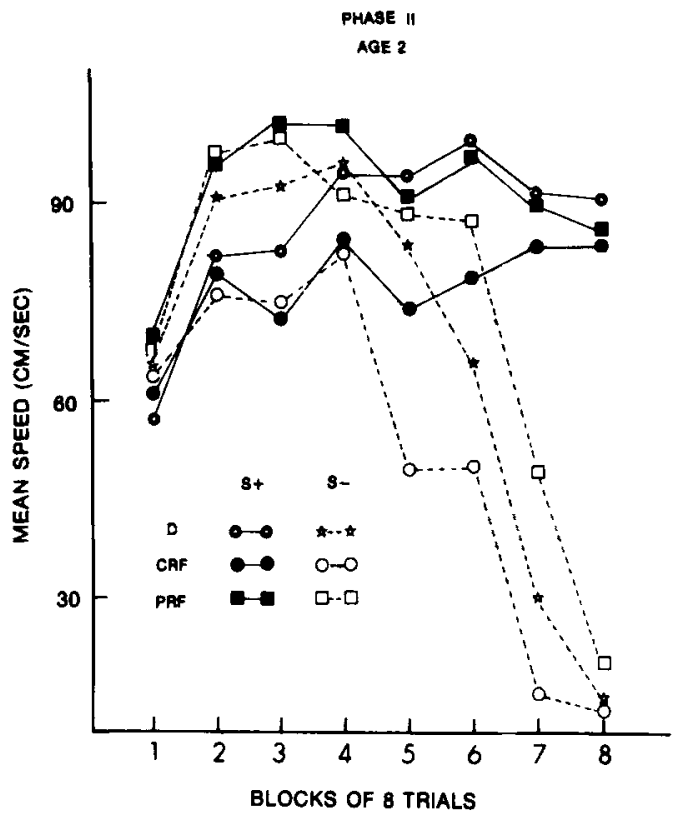

Figure 4. Mean speeds for Age 2 groups in Phase II.

ages, were as fast (Age 1) or faster (Age 2) in Phase II than were animals trained under CRF in Phase I. Thus, unsignaled, random reinforcements in Phase I did not retard Phase II performance. On the other hand, orthogonal comparisons on the first two blocks of trials in Phase II show that D animals of both ages ran significantly more slowly to the new $\mathrm{S}+($ old $\mathrm{S}-$ ) than to the new $\mathrm{S}-[\mathrm{F}(1,48)=$ $8.24, \mathrm{p}<.01$ ]. This is precisely the effect one would predict in the $D$ subjects if an active competing inhibitory (avoidance) response has been conditioned in the presence of the old $S-$. D animals also ran more slowly to $S+$ than PRF animals did to either $S+$ or $S-[F(1,48)=7.02, p<.02]$, though this could have been due as much to the elevated speeds of the PRF animals as to suppression of speeds in the D animals; the PRF animals have learned persistence (see Discussion). Note that, for possibly the same reason, the $D$ animals did not run faster to $S-($ old $S+$ ) than PRF to either $S+$ or $\mathrm{S}-$, as might otherwise be expected.

Analysis of the eight blocks shown in Figures 3 and 4 revealed that behavioral discrimination develops first in Group CRF at both ages, with Groups PRF and D lagging behind. However, a significant Age by Block by Group by Reinforcement interaction effect $[F(10,240)=2.12, p<.02]$ indicates that the behavioral discrimination among groups differed between ages. The PRF and D animals were resistant to discrimination at Age 1, but less so at Age 2. Still, at each age, CRF groups learned more quickly. Orthogonal analyses of Age 1 alone $[C R F$ vs. PRF $+D$ by Reinforcement, $F(1,48)=$ $10.61, \mathrm{p}<.01]$ confirm that Group CRF formed the discrimination significantly faster than either Group PRF or Group D. For Age 2, a significant Group effect $[F(2,24)=11.77, p<.001]$ and a significant orthogonal analysis [CRF vs. PRF $+\mathrm{D}$ by Reinforcement, $F(1,48)=11.68, p<.01]$ reveals that CRF animals learned the discrimination at a faster rate.

The performance of the no-prediscrimination control animals was something of a surprise. No significant main effect or interaction effect for Group was found, indicating that, at both ages, $\mathrm{T}$ and UT performance did not differ. A significant Age by Block by Reinforcement interaction $[F(5,160)=$ 20.30, p $<.001$ ] reveals that Age 1 subjects showed signs of behavioral discrimination only late in training, on the fifth and sixth blocks, and that Age 2 animals did not form the discrimination at all. Although the Age 1 discrimination is statistically real, it developed quite late and was of small magnitude. It appears that animals 25-28 days of age show behavioral discrimination with the use of tactile discriminanda, but that prior CRF training with these stimuli greatly enhances this ability, while animals 29-33 days of age show no evidence of discrimination in the number of trials conducted unless given prior exposure to the stimuli in the context of CRF, PRF, or D training.

\section{DISCUSSION}

The present results clearly demonstrate that conplex learned approach and avoidance response tendencies are retained at least over a 10-day period by infant animals. Apparently, infants are capable of more sophisticated learning and retention than

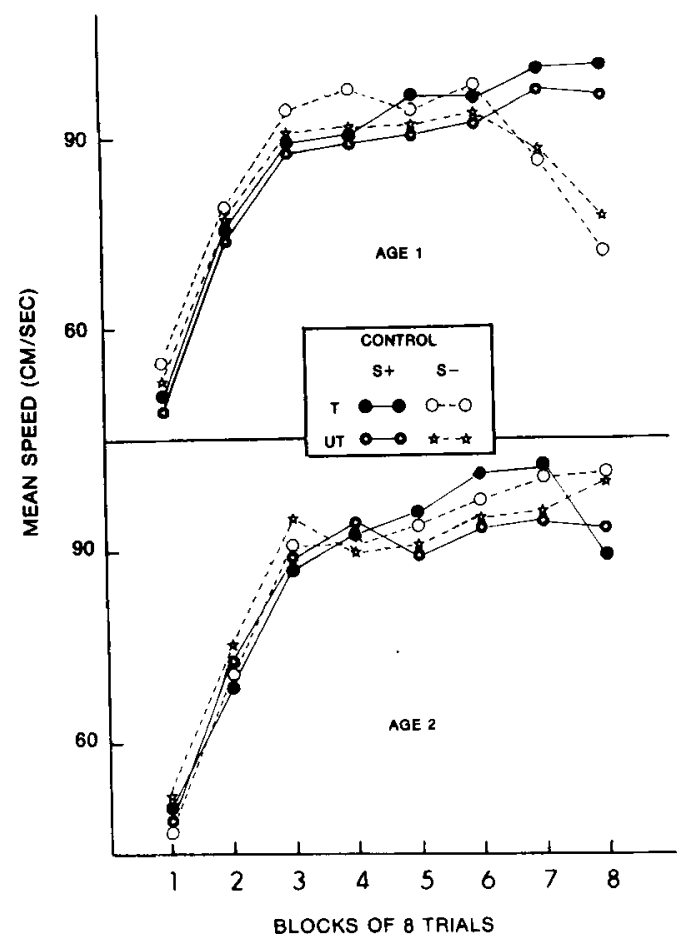

Figure 5. Mean speeds for Age 1 and Age 2 control groups. 
reported by Kenny and Blass (1977). The S - of Phase I was not a "neutral" stimulus in Phase II for D subjects, but had retained inhibitory control over the 10-day interval as shown by the early retardation of running speeds to the new $\mathrm{S}+$ in Phase II. Such "resistance to discrimination" and "resistance to reinforcement" measures have been suggested as indicants of inhibitory control in both operant and discrete trial procedures (Amsel \& Ward, 1965; Hearst, Besely, \& Farthing, 1970). On the other hand, PRF training in Phase I exerted no suppressive effects in the first few blocks of Phase II, even in Age 2 subjects which actually extinguished in Phase I. One implication of these findings is that memory of aversive events is somewhat poorer in infant rats than memory for appetitive events when both events occur in close temporal proximity, unless the aversive event is consistently and explicitly paired with a discrete stimulus.

The implications of the Phase II data, however, are somewhat different. PRF training in Phase I retarded the development of discrimination in Phase II, suggesting retention of the aversive contingency. More specifically, PRF animals may have resolved an approach-avoidance conflict in Phase I by approaching both stimuli (Amsel, 1958), and then retained this counterconditioning in Phase II, resulting in persistent responding to $\mathrm{S}-$ and thus retarding the development of behavioral discrimination. The retardation in the $\mathrm{D}$ groups might also be expected because of the reversal required from Phase I to Phase II. And retention of the conditioned response expectancies might also explain why CRF training in Phase 1 accelerated behavioral discrimination in Phase II (Amsel, 1962; Amsel \& Ward, 1965). Thus, retention of anticipatory nonreinforcement as well as anticipatory reinforcement appears to be quite good, at least over moderately long intervals.

Considering behavioral inhibition in more detail, the current results support the view that appetitive "inhibition" is an active process (e.g., Hearst et al., 1970; Rescorla, 1967), and that behavioral inhibition arises from competing excitatory tendencies (Amsel, 1972). The discrimination shown by $D$ animals in Phase I cannot be attributed simply to a gradual "peaking" of incentive to $\mathrm{S}-$. The slowing of speed to $\mathrm{S}$ - is most likely the result of some active competing response. (The fact that the $\mathrm{S}-$ performance of Age 1 pups did not drop dramatically probably resulted from a "floor effect," as these animals never reached speeds much above baseline.) Visual observation of Group D animals in Phase I tended to confirm the active-avoidance view of inhibition. Late in training on $\mathrm{S}-$ trials, the pup would first bolt from the startbox, and then abruptly stop, turn around, and move back toward the startbox. Perhaps an even more persuasive demonstration of the active nature of response inhibition is seen in the Phase I performance of Age 2 PRF animals. Running speeds for these pups did not reach an asymptote somewhere between the Group D S + and S - performance, as might have been expected from a simple averaging of "excitation" and passive "inhibition"; instead, they rapidly extinguished, probably for the reasons mentioned earlier. This demonstration of quite adequate response inhibition is in accord with a growing body of evidence suggesting that young animals are not nearly as deficient in this respect as at times reported (Amsel et al., 1976; Kenny \& Blass, 1977). It is also worth noting that the apparent deficits in response inhibition observed in hippocampectomized adults often viewed as similar to those in infants have not been demonstrated in many recent experiments (Nadel, O'Keefe, \& Black, 1975), and several investigators in the area are now suggesting that hippocampectomy results in lessened ability to maintain spatial orientations (Black, 1975) or increased motivation to seek stimulus reexposure (Douglas, 1975) rather than a lessened ability to inhibit responding.

Attentional models might help to explain the latedeveloping discrimination of Age 1 no-prediscrimination control animals and the lack of discrimination in Age 2 no-prediscrimination controls. There is ample evidence that adult rats can learn tactile discriminations with between 50 and 90 trials of training (Lovett, 1935; Smith, 1939; Zubeck, 1951). However, 33-day-old rats have difficulty with a simple spatial discrimination (Bronstein \& Spear, 1972). and 30-50-day old rats appear to have much more trouble with successive discriminations than with simultaneous visual discriminations (Roberts, 1966). Further, 30- to 40-day-old rats sometimes show other rather peculiar behaviors in instrumental learning tasks, such as increased retracing in extinction, relative to younger and older animals (Amsel \& Chen, 1976), a somewhat diminished PREE (Burdette et al., 1976, Experiment 1), and poor retention of the PREE under certain conditions (Brake et al., Note 2). In addition, these animals appear to be hypersensitive to environmental stimuli (e.g., Bronstein, 1972). These are all interesting findings, though at this point we can only speculate as to their meaning. Whatever the nature of this peculiar "affliction," the Age 2 controls of the present study appear to be of susceptible age, as do the Age 1 controls, though to a lesser extent (of course, their "abnormal" behavior was also less severe). One obvious interpretation is that there are age-related differences in attentional processing capabilities. This does not seem an unlikely possibility in view of the recent thinking concerning the nature of the limbic system's function mentioned earlier, and of the performance differences obtained in successive, simultaneous, and spatial discrimination tasks (Roberts, 1966). A somewhat different idea, suggested by the work of 
Brennan and Barone (1976) and Frieman, Rohrbaugh, and Riccio (1969) is that, as a result of greater experience with environmental cues, adult rats are better able to respond to discriminative stimuli. Something similar may be happening in our experiments. Perhaps extensive experience with discriminanda during infancy somehow insures that those stimuli will be salient for 25- and especially 30-day-old animals when they normally would not be. In any case, it is interesting to note that early handling and deprivation manipulations by themselves had no differential effects on thie control animals.

The present results also extend earlier findings (Amsel et al., 1977) with respect to the effectiveness of dry suckling as a reinforcing event. The fact that CRF animals at both ages reached higher absolute speeds than did PRF animals in Phase $I$ can be directly attributed to the relative reward expectancies of the two groups. However, dry suckling for older animals, though clearly reinforcing, becomes less able to support approach behavior in the face of a tendency to avoid. This is vividly illustrated by Age 2 PRF animals, which, after some initial acquisition, actually began to extinguish. The idea that dry suckling lose some of its incentive value between 15 to 18 days of age is supported by experiments showing that pups often detach from dry nipples while attempting to nurse at that age, while pups younger than 14 days of age remain attached to dry nipples for hours (Hall et al., 1975; Brake et al., Note 1). Further, the loss of reinforcing value for dry suckling in pups 15 to 18 days of age coincides with the development of other systems in the animal. At this age, rat pups open their eyes, wander from the nest, and initiate suckling independently of the dam (Bolles \& Woods, 1964). They also begin to thermoregulate (Fowler \& Kellog, 1975) and respond to a pheromone which the dam begins to secrete at this time (Leon, 1974, 1975). In short, as the animal becomes more "instrumental," some kinds of maternal stimuli are less needed and these stimuli may lose reinforcing properties.

The finding that infant rats are able to learn and inhibit appetitive responses suggests that nursing behaviors themselves may be learned responses, at least in part. Several investigators have found that suckling and attachment behaviors are less invariant than previously believed (Hall \& Rosenblatt, 1977; Brake et al., Note 1). Further, the olfactory attractant thought to be on the nipples of lactating dams (Hofer, Shair, and Singh, 1976; Teicher \& Blass, 1976) might gain salience through a conditioning process (Teicher \& Blass, 1977). Another response that may be modified through learning is the anticipatory "treadle" response characteristically made by nursing pups immediately prior to a milk ejection from the dam (Drewett et al., 1974). A particularly exciting possibility is that the infant rat might learn persistent suckling behavior. Such learning might proceed "incidently" as the pups' frequent suckling bouts are only partially "reinforced" due to the intermittant nature of the dam's milkejection schedule. Of course, several issues need to be addressed (the reward value of milk, the nonnutritive value of suckling, etc.) before such a hypothesis can be seriously entertained, but the results of the present study clearly demonstrate that infants at least as young as 11-14 days of age are capable of learning and retaining the complex approach and avoidance tendencies that would be required.

\section{REFERENCE NOTES}

1. Brake, S. C., Wolfson, V., \& Hofer, M. A. Electrophysiological patterns associated with non-nutritive suckling in 11-13-dayold rat pups. Manuscript submitted for publication.

2. Brake, S. C., Burdette, D. R., Chen, J. S., \& Amsel, A. Ontogeny of persistence: Retention of persistence in 19. and 33-day-old rats as a function of the number of reqcquisition trials and length of retention interval. In preparation.

\section{REFERENCES}

Altman, J., Brunner, R. L., \& Bayer, S. A. The hippocampus and behavioral maturation. Behavioral Biology, 1973, 8 , 557-596.

AMSEL, A. The role of frustrative nonreward in noncontinuous reward situations. Psychological Bulletin, 1958, 55, 102-119.

AMSEL, A. Frustrative nonreward in partial reinforcement and discrimination learning: Some recent history and a theoretical extension. Psychological Review, 1962, 69, 306-328.

AMSEL, A. Inhibition and mediation in classical, Pavlovian and instrumental conditioning. In R. A. Boakes \& M. A. Halliday (Eds.), Inhibition and learning. London: Academic Press. 1972.

Amsel, A., Burdette, D. R., \& Letz, R. Appetitive learning, patterned alternation, and extinction in 10-day-old rats with non-lactating suckling as reward. Nature, 1976, 262, 816-818.

AMSEL, A., \& ChEN, J. S. Ontogeny of persistence: Immediate and long-term persistence in rats varying in training age between 17 and 65 days. Journal of Comparative and Physiological Psychology, 1976, 90, 808-820.

Amsel, A., Letz, R., \& Burdette, D. R. Appetitive learning and extinction in 11-day-old rat pups: Effects of various reinforcement conditions. Journal of Comparative and Physiological Psychology, 1977, 91, 1156-1167.

AMsel, A., \& WARD, J. S. Frustration and persistence: Resistance to discrimination following prior experience with the discriminanda. Psychological Monographs, 1965, 79(4, Whole No. 597).

BLACK, A. H. Hippocampal electrical activity and behavior. In R. L. Isaacson \& K. H. Pribram (Eds.), The hippocampus (Vol. 2) Neurophysiology and behavior. New York: Plenum Press, 1975

Bolles, R. C., \& Woods, P. C. The ontogeny of behavior in the albino rat. Animal Behaviour, 1964, 12, 427-441.

Brennan, J. F., \& Barone, R. J. Effects of differential cue availability in an active avoidance CS for young and adult rats. Developmental Psychobiology, 1976, 9, 237-244.

Bronstein, P. M. Repeated trials with the albino rat in the open field as a function of age and deprivation. Journal of Comparative and Physiological Psychology, 1972. 81, 84-93.

Bronstein, P. M., Neiman, H., Wolkoff, F. D., \& Levine, M. J. The development of habituation in the rat. Animal Learning \& Behavior, 1974, 2. 92-96.

Bronstein, P. M.. \& Spear, N. E. Acquisition of a spatial discrimination by rats as a function of age. Journal of Comparative 
and Physiological Psychology, 1972, 78, 208-212.

Brunner, R. L. Age differences in one-trial passive avoidance. Psychonomic Science, 1969, 14, 134.

Bulut, F. G., \& Altman, J. Spatial and tactile discrimination learning in infant rats motivated by homing. Developmental Psychobiology, 1974, 7, 465-473.

Burdette. D. R., Brake, S. C., Chen, J. S., \& Amsel, A Ontogeny of persistence: Immediate extinction effects in preweanling and weanling rats. Animal Learning \& Behavior, 1976. $4,131-138$.

CampBell, B. A. Developmental studies of learning and motivation in infa-primate mammals. In H. W. Stevenson, E. H. Hess. \& H. L. Rheingold (Eds.), Early behavior: Comparative and developmental approaches. New York: Wiley, 1967.

Campbell, B. A., \& Campbell, E. H. Retention and extinction of learned fear in infant and adult rats. Joumal of Comparative and Physiological Psychology. 1962, 55, 1-8.

Campbell, B. A.. Jaynes, J., \& Misanin, J. R. Retention of a light-dark discrimination in rats of different ages. Journal of Comparative and Physiological Psychology, 1968, 66, 467-472.

Campbell, B. A., Lytle, L. D., \& Fibiger, H. C. Ontogeny of adrenergic arousal and cholinergic inhibitory mechanisms in the rat. Science, 1969, 166, 635-636.

Campbell, B. A., \& Mabry, P. D. Ontogeny of behavioral arousal: A comparative study. Journal of Comparative and Physiological Psychology, 1972. 81, 371-379.

Campbell, B. A., Misanin, J. R.. White, B. C., \& Lytle, L. D. Species differences in ontogeny of memory: Indirect support for neural maturation as a determinant of forgetting. Journal of Comparative and Physiological Psychology, 1974, 87, 193-202.

Campbell, B. A., \& Randall, P. K. The effect of reinstatement stimulus conditions on the mantenance of long-term memory. Developmental Psychobiology, 1976, 9. 325-333.

Chen, J.S., \& AMSEL, A. Retention and durability of persistence acquired by young and infant rats. Journal of Comparative and Physiological Psychology, 1975. 89, 238-245.

Coulter, X., Collier, A. C., \& Camprell, B. A. Long-term retention of early Pavlovian fear conditioning in infant rats. Journal of Experimental Psychology: Animal Behavior Processes, $1976,1,48-56$

Douglas, R. J. The development of hippocampal function: Implications for theory and therapy. In R. L. Isaacson \& K. H. Pribram (Eds.), The Hippocampus (Vol. 2) Neurophvsiology and behavior. New York: Plenum Press, 1975.

Douglas, R. J., Peterson, J. L., \& Douglas, D. P. The ontogeny of a hippocampus-dependent response in two rodent species. Behavioral Biology, 1973, 8, 27-37.

Drewett, R. F., Statham, C., \& Wakerley, J. B. A quantitative analysis of the feeding behavior of suckling rats. Animal Behaviour, 1974, 22, 907-913.

Egger, G. J., \& Livesey, P. J. Age effects in the acquisition and retention of active and passive avoidance learning by rats. Developmental Psychobiology, 1972, 5, 343-351.

Egger, G. J., Livesey, P. J., \& Dawson, R. G. Ontogenic aspects of central cholinergic involvement in spontaneous alternation behavior. Developmental Psychobiology. 1973. 6. 289.299.

Feigley, D. A., Parsons, P. J., Hamilton, L. W., \& Spear, N. E. Development of habituation to environments in the rat. Journal of Comparative and Physiological Psychology, 1972, 79, 443-452.

Feigley, D. A., \& Spear, N. E. Effect of age and punishment condition on long-term retention by the rat of active and passive avoidance learning. Journal of Comparative and Physiological Psychology, 1970, 73, 515-526.

Fowler, S. J., \& Kellog, C. Ontogeny of thermoregulation mechanisms in the rat. Journal of Comparative Physiological
Psychology, 1975, 89, 738-746.

Frieman, J. P., Rohrbaugh, M.. \& Riccio, D. C. Age differences in the control of acquired fear by tone. Canadian Journal of Psychology, 1969, 23, 237-244.

Hall, W. G., Cramer, C. P., \& Blass, E. M. Developmental changes ir suckling of rat pups. Nature, 1975, 258, 318-320.

Hall, W. G. \& Rosenblatr, J. S. Suckling behavior and intake control in the developing rat pup. Journal of Comparative and Physiologicai Psychology, 1977, 91, 1232-1247.

Hearst, E., Besley, S.. \& Farthing, G. W. Inhibition and the stimulus control of operant behavior. Journal of the Experimental Analysis of Behavior. 1970, 14, 373-409.

Hofer, M. A., Shair, H., \& Singh, P. Evidence that maternal ventral skin substances promote suckling in infant rats. Physiology \& Behavior, 1976, 17, 131-137.

Kenny, J. T., \& Blass, E. M. Suckling as incentive to instrumental learning in preweanling rats. Science, 1977. 196, 898-899.

KIRBy, R. H. Acquisition, extinction and retention of an avoidance response in rats as a function of age. Journal of Comparative and Physiological Psychology, 1963, 56, 158-162.

LEon, M. Maternal pheremone. Physiology \& Behavior, 1974, 13. 441.453

LEON, M. Dietary control of maternal pheremone in the lactating rat. Physiology \& Behavior, 1975, 14, 311-319.

Lincoln, D. W., Hill, A..\& Wakerley, J. B. The milk ejection reflex of the rat: An intermittant function not abolished by surgical levels of anaesthesia. Journal of Endrocrinology, 1973, 57, 459-476.

Lovetr, D. Spinal mechanisms involved in solving problems in sensory discrimination. III. The ability of rats with spinal cord lesions to discriminate runways differing in tactual discriminanda. Psychological Bulletin, 1935, 32. 540 .

Moorcroft, W. H. Ontogeny of forebrain inhibition of behavioral arousal in the rat. Brain Research, 1971, 35, 513-522.

NAdel, L., O'KeEfe, J., \& Black, A. Slam on the brakes: A critique of Altman, Brunner, and Bayer's response-inhibiting model of hippocampal function. Behavioral Biology, 1975, 14, 151-162.

Rescorla, R. A. Pavlovian conditioning and its proper control procedures. Psychological Review, 1967, 74, 71-80.

Riccio, D. C.. Rohrbaugh, M.. \& Hodges, L. A. Developmental aspects of passive and active avoidance learning in rats. Developmental Psychobiology, 1968, 1. 108-111.

RoBERTs, W. A. Learning and motivation in the immature rat. American Journal of Psychology, 1966, 79, 3-23.

Sмiтн, D. E. Cerebral localization in somesthetic discrimination in the rat. Joumal of Comparative Psychology, 1939, 28, 161-188.

SMITH, N. Effects of interpolated learning on the retention of an escape response in rats as a function of age. Joumal of Comparative and Physiological Psychology, 1968, 65, 422-426.

Tercher, M. H., \& Blass, E. Suck ling in newborn rats eliminated by nipple lavage and reinstated by pup saliva. Science, 1976, 193, $422-424$.

Teicher, M. H., \& Blass, E. M. First suckling response of the newborn albino rat: Roles of olfaction and amniotic fluid. Science. 1977, 198, 635-636.

W AKerley, J. B., \& Drewett, R. E. Patterns of suckling in the infant rat during spontaneous milk ejection. Physiology \& Behavior, 1975, 15, 277-281.

Zubek. J. P. Studies in somesthesis. 1. Role of the somesthetic cortex in roughness discrimination in the rat. Journal of Compar ative and Physiological Psychology, 1951, 44, 339.

(Received for publication October 28, 1977; revision accepted April 6. 1978.) 